\title{
PENGARUH DIP TIME PADA UNIT PROCESSOR TERHADAP LINEARISASI PLATE CETAK
}

\author{
Cholid Mawardi $^{1 凶}$, Zakhi Firmansyah ${ }^{2}$, Untung Basuki ${ }^{3}$ \\ Jurusan Teknik Grafika, Politeknik Negeri Media Kreatif, Jagakarsa, Jakarta Selatan, 12640

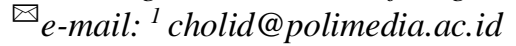

\begin{abstract}
This study aims to analyze the effect of the parameters on the processing unit on the quality of the printing plate. The parameters used in this study use the immersion time method. This research activity also aims to be able to know the real picture of the effect of changes in immersion time on the quality of the printed plate. Expected results of research on the effect of immersion time on the quality of printing plates, namely the extent to which immersion time affects the quality of Computer to Plate (CtP) plates to be printed on offset printing machines. Next, the researchers will also formulate problems that arise due to the development of plaques and provide solutions. This research should be a reference for users involved in improving print quality. For the printing industry can be used as a material consideration in the process of manufacturing quality printing plates for the good of the printing industry which is good at global competition.
\end{abstract}

Keywords: Quality, plate CtP, dip time

\begin{abstract}
Abstrak
Penelitian ini bertujuan untuk menganalisis pengaruh parameter yang ada pada unit processor terhadap kualitas plate cetak. Parameter yang digunakan pada penelitian ini yaitu menggunakan metode dip time. Kegiatan penelitian ini juga memiliki tujuan untuk dapat mengetahui gambaran nyata pengaruh perubahan dip time terhadap kualitas plate cetak. Hasil yang diharapkan terhadap penelitian tentang pengaruh dip time terhadap kualitas plate cetak, yaitu sejauh mana dip time mempengaruhi kualitas plate Computer to Plate (CtP) yang akan dicetak pada mesin cetak offset. Kemudian peneliti juga akan merumuskan masalah-masalah yang terjadi akibat pengembangan plate dan memberikan solusinya serta Penelitian ini diharapkan dapat menjadi salah satu rujukan bagi pengguna yang berkecimpung dalam meningkatkan mutu cetak. Untuk industri percetakan dapat dijadikan sebagai bahan pertimbangan dalam pengerjaan proses pembuatan plate cetak yang berkualitas demi industri cetak yang baik pada persaingan global.
\end{abstract}

Kata kunci: kualitas, plate CtP, dip time

\section{Pendahuluan}

Pada saat ini industri percetakan mengalami perkembangan yang sangat pesat, sejalan dengan munculnya perkembangan pada mesin cetak. Oleh karena itu hasil cetakan merupakan kebutuhan yang tidak lepas dari kehidupan masyarakat sehari-hari [1]. Semakin berkembangannya teknologi maka semakin tinggi pula tuntutan masyarakat terhadap hasil cetakan. Agar tuntutan tersebut dapat dipenuhi maka perlu meningkatkan pengetahuan tentang hasil kualitas cetak. Di pasar cetak saat ini, pengurangan biaya, keramahan lingkungan dan peningkatan produktivitas sangat dibutuhkan. Untuk mencapai semua tujuan itu sekaligus efektif untuk menerapkan konsep penghematan sumber daya untuk mengurangi limbah secara material, jumlah proses, energi, emisi, dan air secara komprehensif. [2]

Kualitas cetakan dapat dilihat dari beberapa faktor [3], contohnya faktor plate. Plate merupakan suatu bahan baku utama sebagai acuan proses terjadinya pencetakan didalam produksi. Tanpa menggunakan plate, mesin yang akan digunakan untuk mencetak tidak dapat beroperasi. Dengan demikian, plate 
merupakan acuan dari cetak offset yang sangat penting bagi proses pencetakan, dan untuk tujuan ini ada baiknya melakukan pengendalian kualitas pada plate cetak [4].

Dari beberapa studi literatur yang peneliti dapatkan, maka penelitian ini mengusulkan untuk menganalisis pengaruh dip time pada unit processor terhadap kualitas plate cetak.

\section{Metode Penelitian}

\section{1) Lokasi Penelitian}

Lokasi penelitian dilakukan di Laboratorium Prepress, Politeknik Negeri Media Kreatif, Jakarta.

\section{2) Metode Penelitian}

Metode penelitian dapat dilihat pada Gambar 1, dimana pengujian dibagi menjadi 3 dip time yakni pada waktu nilai dip time 18, 38, dan 55 dengan parameter suhu dan conductivity dibuat tetap. Dip time dilakukan dengan perputaran masukan plate yang dihitung berdasarkan waktu 18 second, 36 second hingga 55 second dengan parameter kualitas raster diukur skala minimal dan maksimal raster $0 \%$ hingga $100 \%$. Dengan adanya perbedaan waktu tersebut maka penelitian ini akan dilihat secara langsung kualitas plate cetak mana yang memiliki kemampuan terbaik jika diukur mengunakan dip time pada mesin processor serta dilakukan pengujian eksperimental dua plate masing-masing dengan berbagai jenis bentuk dot shape [5]. Secara garis besar pula metode penelitian terdiri atas pengumpulan plate cetak, pembentukan image pada plate dengan mesin CtP, pengembangan image pada plat dengan mesin processor, perubahan parameter dip time pada unit processor dan evaluasi hasil.

\section{3) Teknik Pengumpulan Data}

Teknik pengumpulan data yang digunakan pada penelitian ini yaitu dengan cara melakukan beberapa sampel percobaan yang dilakukan pada unit laboratorium prepress. Sampel plate cetak yang digunakan dalam penelitian ini diproduksi dalam kondisi standar oleh produsen plate cetak [6].

\section{a. Kerangka Pikir Penelitian}

Kerangka pemikiran merupakan skema yang menjelaskan suatu penelitian yang akan diteliti diantaranya untuk mendapatkan gambaran lengkap tentang pengaruh dip time pada unit processor terhadap kualitas plate CtP.

b. Jenis Peralatan yang dipergunakan

1. Jenis alat ukur dan alat loupe

- IC plate 2 alat ukur untuk plate cetak

- Alat ukur conductivity chemical

- Loupe MG 10085-2

- $\quad$ Spectro Densitometer X-Rite

2. Jenis mesin Computer to Plate (CtP)

- Mesin CtP Kodak

- Processor/mesin pengembang Kodak

3. Jenis Bahan

- Plate CtP

- Developer (bahan pengembang)

- Replenisher

- Gum

- Air

\section{c. Langkah Kerja Penelitian}

Sesuai dengan judul maka langkah kerja pada penelitian ini yaitu :

1. Melakukan pengukuran temperatur bahan pengembangan (developer) pada unit processor.

2. Melakukan pengukuran density dan dot gain plate $\mathrm{CtP}$ setelah dikembangkan dengan spectro densitometer plate cetak atau IC Plate 2 [7].

3. Melakukan analisis data hasil pengukuran dot gain [8].

\section{Hasil dan Pembahasan}

1) Pembentukan Image pada plate di unit mesin imaging $\mathrm{CtP}$

Pada proses awal penelitian ini dilakukan pembentukan image pada 
plate dengan menggunakan mesin imaging CtP Kodak Trendsetter 800 III. Screening yang digunakan yaitu Amplitude Modulation (AM), screen rulling 150 lpi dan bentuk dot yang dipilih yaitu bentuk round-square (Euqlidean). Adapun proses pembentukan image pada plate dapat diilustrasikan dengan menggunakan Virtual Proofing System (VPS).

Perbandingan proses pembentukan image plate menggunakan Virtual Proofing System (VPS) seperti yang terlihat pada Gambar 2 s.d Gambar 5. memiliki hasil:

Tabel 1. Perbandingan Imaging Plate dengan VPS

\begin{tabular}{cccc}
\hline No & Warna & Bentuk & Sudut \\
\hline 1 & Cyan & $\begin{array}{l}\text { round- } \\
\text { square }\end{array}$ & $165^{\circ}$ \\
\hline 2 & Magenta & $\begin{array}{l}\text { round- } \\
\text { square }\end{array}$ & $105^{\circ}$ \\
\hline 3 & Yellow & $\begin{array}{l}\text { round- } \\
\text { square }\end{array}$ & $0^{\circ}$ \\
\hline 4 & Black & $\begin{array}{l}\text { round- } \\
\text { square }\end{array}$ & $45^{\circ}$ \\
& &
\end{tabular}

Skema warna cyan, magenta, yellow dan black dikukur dengan memiliki bentuk dot yang sama yakni round square namun memilki sudut yang berbedabeda. Fungsi dari hasil perbandingan ini adalah untuk mengetahui masing masing dari warna agar dapat diidentifikasi oleh mesin processor dan dilanjutkan pengukuran linerarisasi.

\section{2) Pengembangan image pada Plate di unit Mesin Processor}

Pada proses ini dilakukan pengembangan image pada plate dengan menggunakan mesin Processor. Proses ini merupakan lanjutan dari proses pengembangan plate pada unit imaging. Parameter yang ada pada mesin processor ini adalah dip time, suhu dan conduktivity. Pada penelitian ini dilakukan perubahan parameter yang ada pada unit mesin processor yaitu dengan melakukan perubahan pada parameter Dip time. Percobaan dilakukan yaitu pada nilai dip time 18, 38, dan 55 dengan parameter suhu dan conductivity dibuat tetap.

\section{3) Perubahan Parameter Dip time pada} Unit Mesin Processor

Kualitas plate ditentukan dari hasil pembentukan raster yang didapat pada hasil akhir yaitu pada unit processor. Pada proses ini dilakukan pengukuran raster dari $0 \quad \%$ hingga $100 \%$. Pengukuran dikatakan baik jika pada raster input linear dengan raster output atau dapat dikatakan linearisasi. Sebagai contoh untuk raster $10 \%$ pada input harus menghasilkan raster $10 \%$ pada output dengan batas toleransi sebesar +$2 \%$, begitu pula untuk raster selanjutnya. Sehingga kualitas plate dipengaruhi dari hasil pengukuran linearisasi tersebut, semakin linear hasil yang didapatkan maka semakin baik kualitas dari plate cetak tersebut. Pengukuran linearisasi dilakukan dengan menggunakan alat ukur Spektro densitometer X-Rite. Berikut hasil yang didapat dari perubahan parameter dip time pada unit mesin processor yaitu seperti terlihat pada Gambar 6, 7 dan 8.

Berdasarkan grafik pada Gambar 6, maka dapat dianalisis untuk nilai Dip time 18 mengakibatkan nilai raster pada area highlight cenderung mengalami kenaikan nilai persentase raster. Pada raster $10 \%$ hasil yang didapatkan sebesar $19 \%$, terjadi kenaikan sebesar 9\% sehingga dapat dikatakan melebihi batas toleransi yang diharapkan dan grafik yang dihasilkan tidak linear.

Hasil yang didapat untuk nilai Dip time 38 dan Suhu 23 seperti terlihat pada grafik Gambar 7, yaitu nilai raster pada area highlight dan shadow sangat stabil, sebagai contoh pada raster $20 \%$, hasil pengukuran yang didapatkan sebesar $20 \%$, walaupun ada beberapa raster yang tidak tepat sama namun masih berada pada batas toleransi +- 2\%. Sehingga dapat dikatakan pada percobaan ini menghasilkan grafik yang linear.

Berdasarkan grafik pada Gambar 8, maka dapat dianalisis untuk nilai Dip 
time 55 mengakibatkan nilai raster pada area highlight dan shadow cenderung mengalami penuruanan nilai persentase raster. Pada raster $10 \%$ hasil yang didapatkan sebesar $7 \%$, terjadi penurunan sebesar 3\%. Sehingga dapat dikatakan melebihi batas toleransi yang diharapkan dan grafik yang dihasilkan tidak linear.

Dari percobaan yang telah dilakukan maka nilai dip time berpengaruh atau sensitif terhadap linearisasi dot, seperti terlihat pada Gambar 9. Gambar tersebut menjelaskan bahwa setelah dilakukan percobaan pada kesemua nilai dip time, baik pada 18 second, 38 second, bahkan 55 second. Grafik yang menunjukan nilai sensitif terhadap linearisasi dot berada pada percobaan dip time 18, dimana pada raster $10 \%$ hasil yang didapatkan sebesar 19\%, terjadi kenaikan sebesar 9\%. Kenaikan ini menunjukan hasil yang lebih tinggi dibandingan percobaan dip time 38 dan 55 .

\section{Kesimpulan}

Hasil percobaan pada penelitian ini menunjukkan bahwa linearisasi atau kualitas plate cetak yang dihasilkan sensitif terhadap perubahan dip time pada unit processor. Berdasarkan hasil yang diperoleh dari penelitian ini, kualitas terbaik dihasilkan pada nilai dip time sebesar 38 detik. Dip time yang terlalu rendah mengakibatkan kenaikan nilai raster, sedangkan dip time yang terlalu tinggi mengakibatkan penurunan nilai raster.

\section{Daftar Pustaka}

[1] Dameria, Ane. 2008. Basic printing. Link \& Match Graphics, 2008

[2] Kotaro Kudo, Watanabe noriaki, Sonokawa Koji, Tomoyoshi
Mitsumoto, Kyosuke Tsumura, Tadao Shibamoto ,Taira Murakami, 2017, Development of Processless CTP Plates with High Printing Durability and Adaptability to $U V$ Ink Printing, Fujifilm Reseaarch Development no, 62-2017.

[3] Kiphan, Helmut, 2011. Handbook of Printer Media, Germany, Heidelberg,

[4] Speirs, hugh, 2009. Introduction to prepress 2nd edition, Pira International,

[5] Miljković, P., Valdec, D., \& Matijević, M. (2018). The impact of printing substrate on dot deformation in flexography. Tehnicki Vjesnik, 25, 509-515.

https://doi.org/10.17559/TV20170710152140

[6] Tomašegovic, T., Beynon, D., Claypole, T., \& Poljacek, S. M. (2017). Modifying the qualitative properties of print by surface treatment of flexographic printing plate. Journal of Print and Media Technology Research, 6(2), 57-68. https://doi.org/10.14622/JPMTR1704

[7] Baral, Anjan Kumar; Tanan, Nupur; Gupta, Chetna. 2016 Study of Solid Ink Density, Dot Gain and Print Contrast on Various Grades of Paper Print on Dry Toner Based Digital Press, International Journal of Science, Engineering and Computer Technology; Hisar Vol. 6, Iss. 3, (Sep 2016)

[8] Sharma, Deepak Kumar; Rani, Ruby, 2016. Analysis of the Relationship between Solid Ink Density, Dot Gain and Print Contrast in Digital Printing. International Journal of Science, Engineering and Computer Technology,Hisar Vol. 6, Iss. 2, (Ju ne 2016): 130-131. 


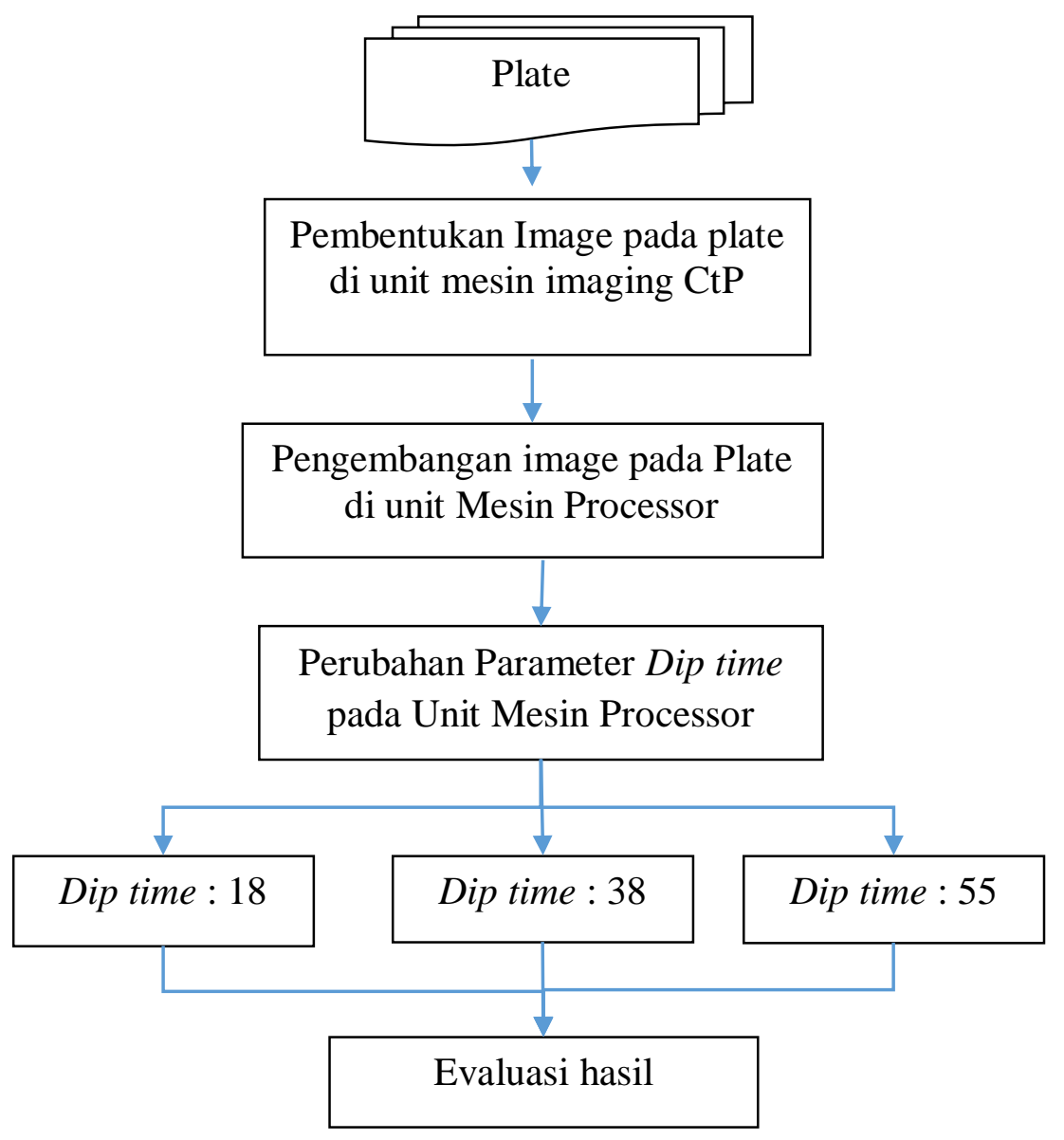

Gambar 1. Alir Metode Penelitian

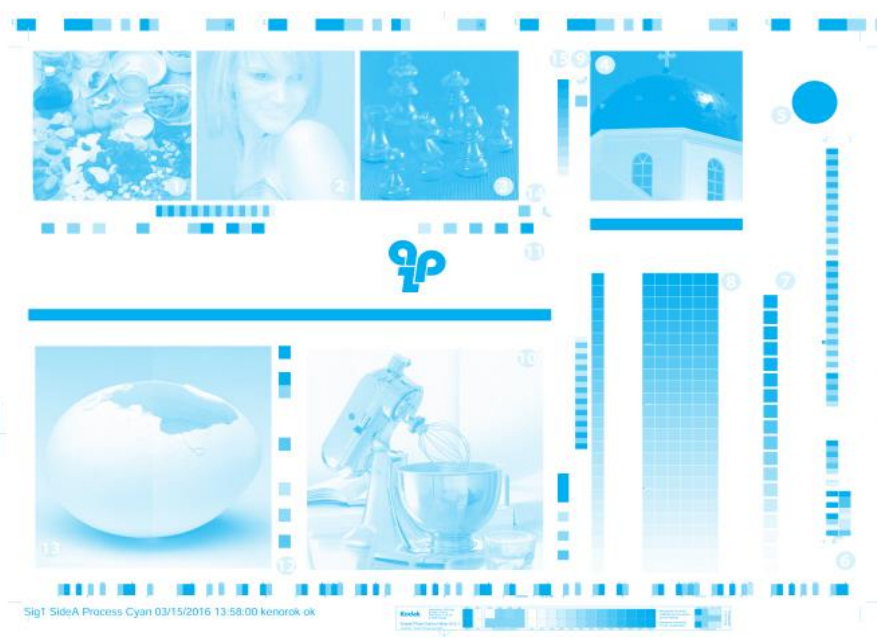

Gambar 2. Virtual Proofing Untuk Warna Cyan 
Cholid Mawardi dkk, Pengaruh Dip Time...

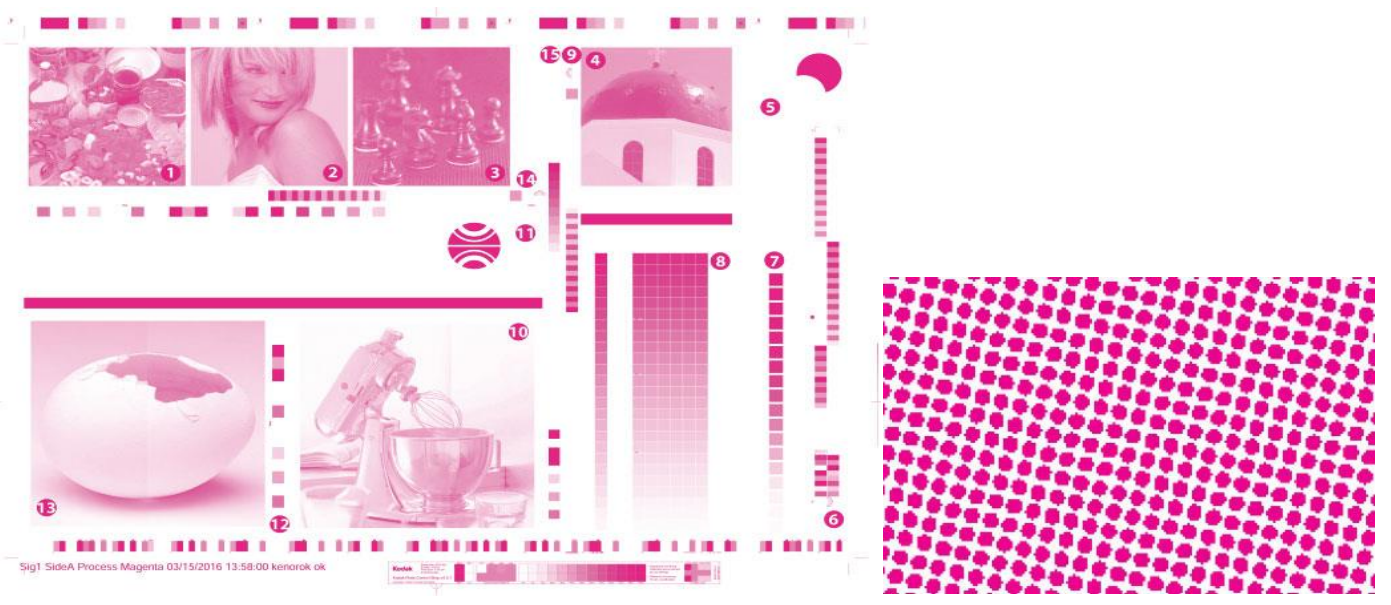

Gambar 3. Virtual Proofing untuk Warna Magenta

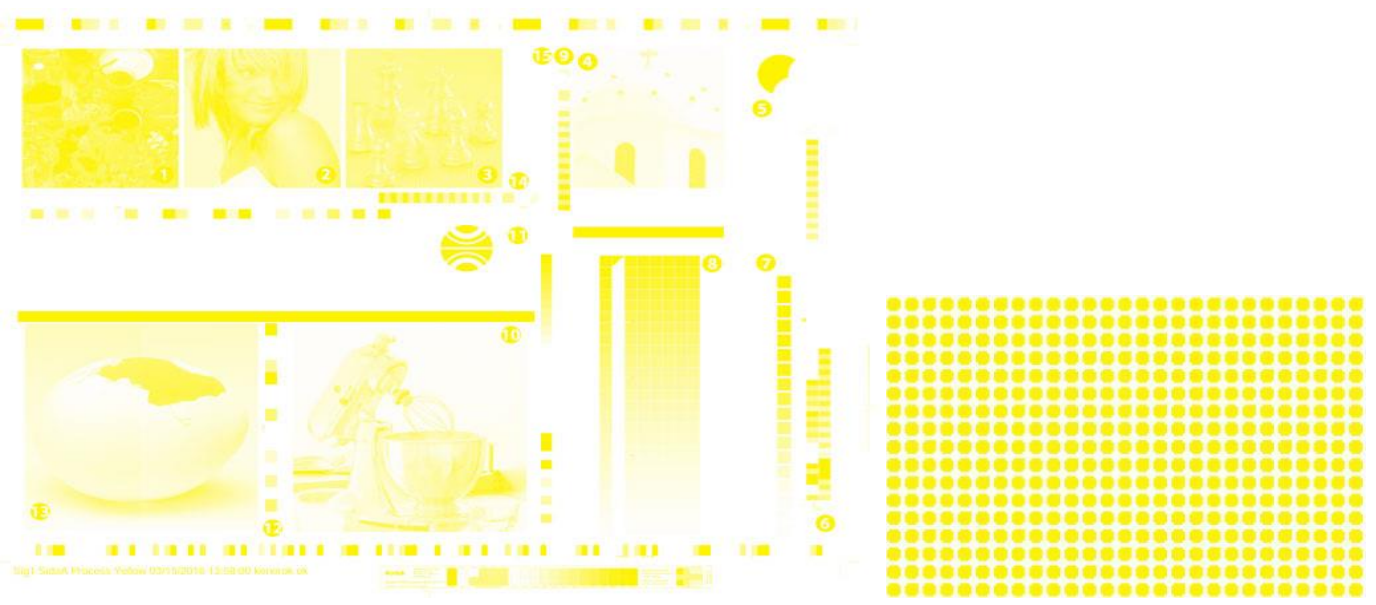

Gambar 4. Virtual Proofing untuk Warna Yellow

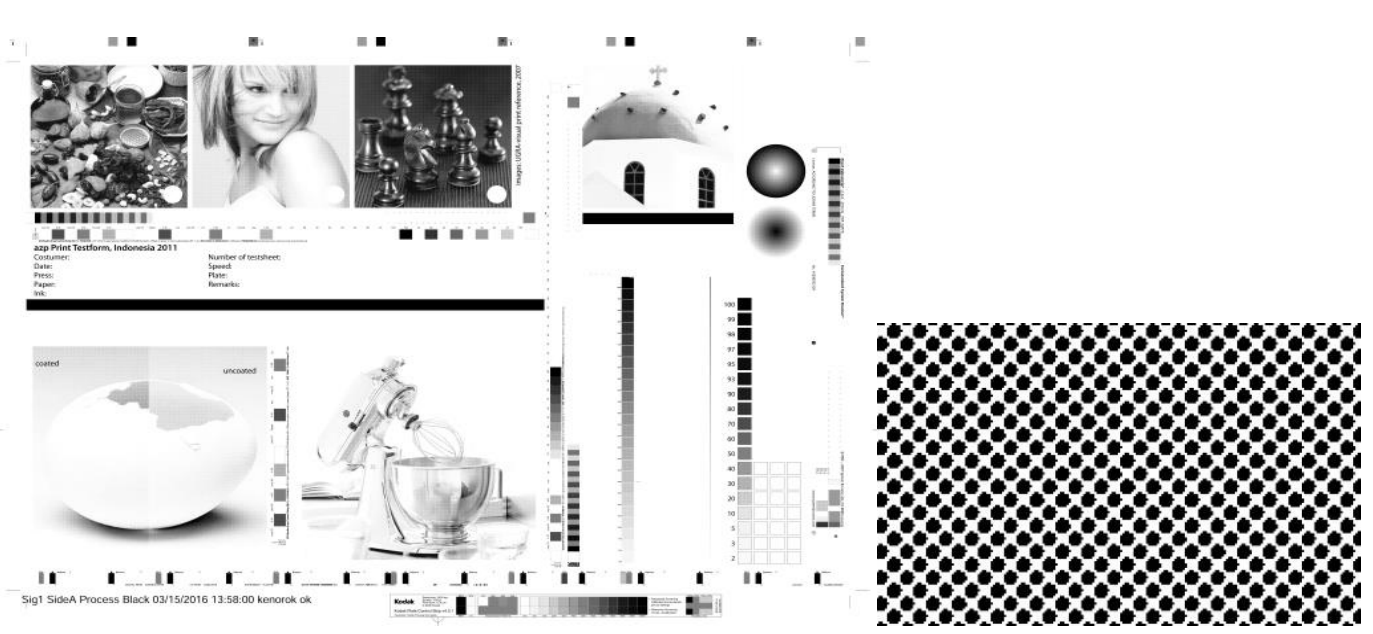

Gambar 5. Virtual Proofing untuk Warna Black 

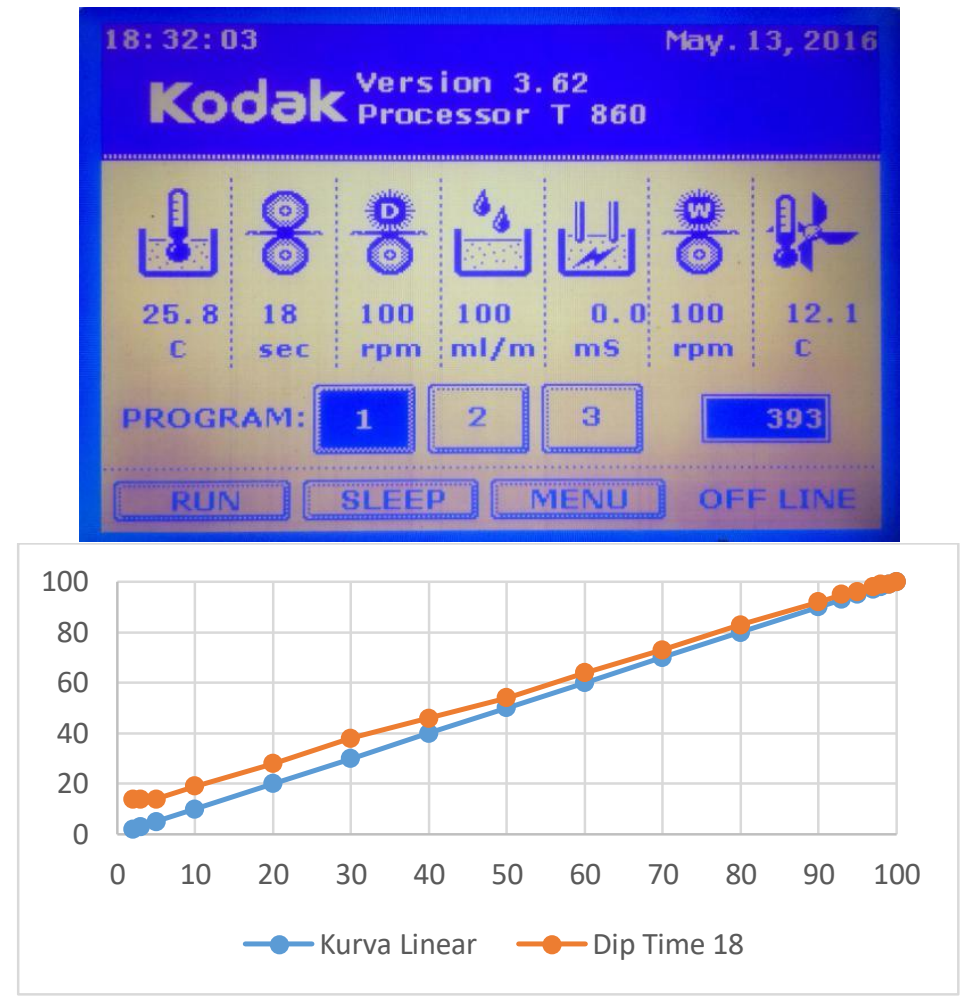

Gambar 6. Percobaan Pada Nilai Dip Time 18
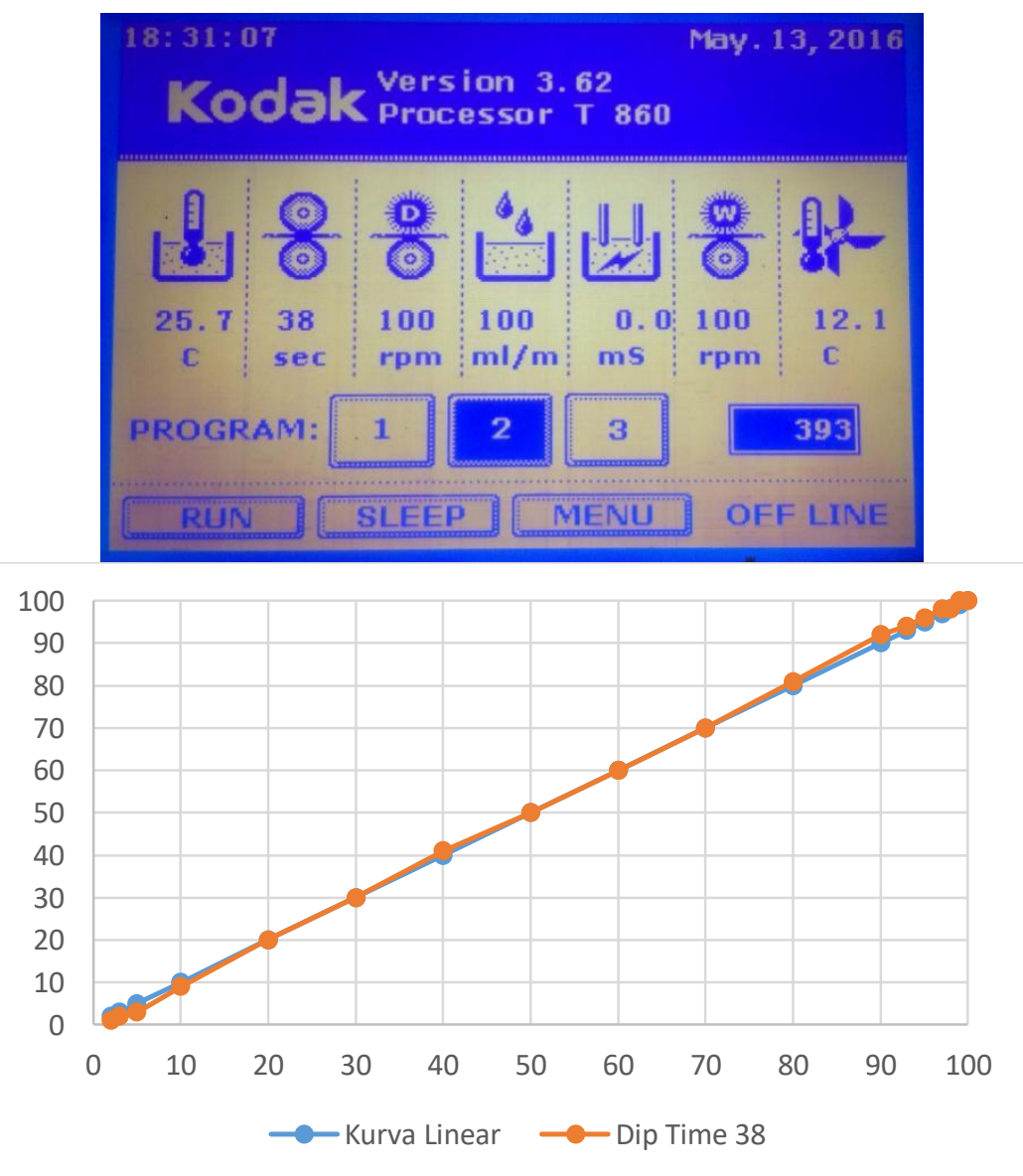

Gambar 7. Percobaan pada Nilai Dip Time 38 
Cholid Mawardi dkk, Pengaruh Dip Time...

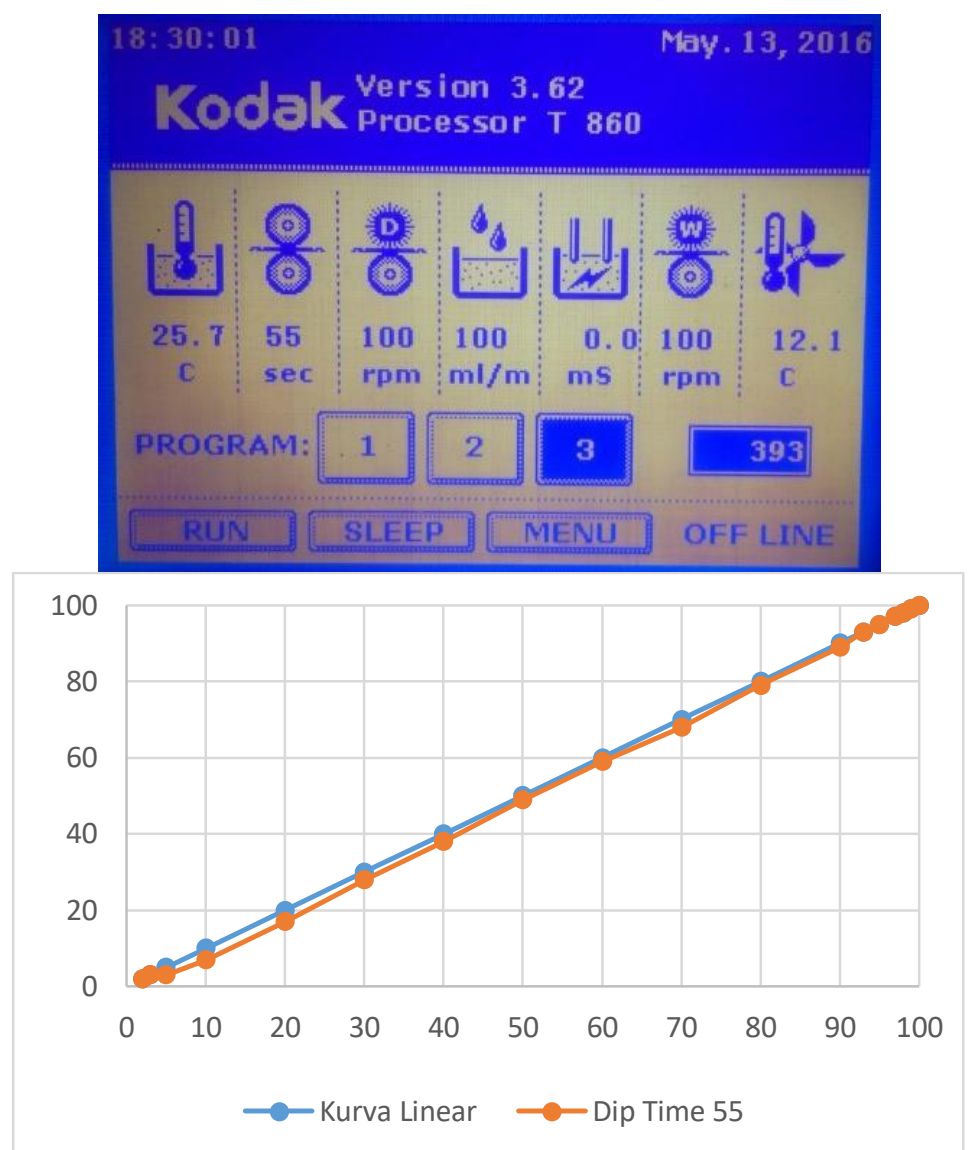

Gambar 8. Percobaan Pada Nilai Dip Time 55

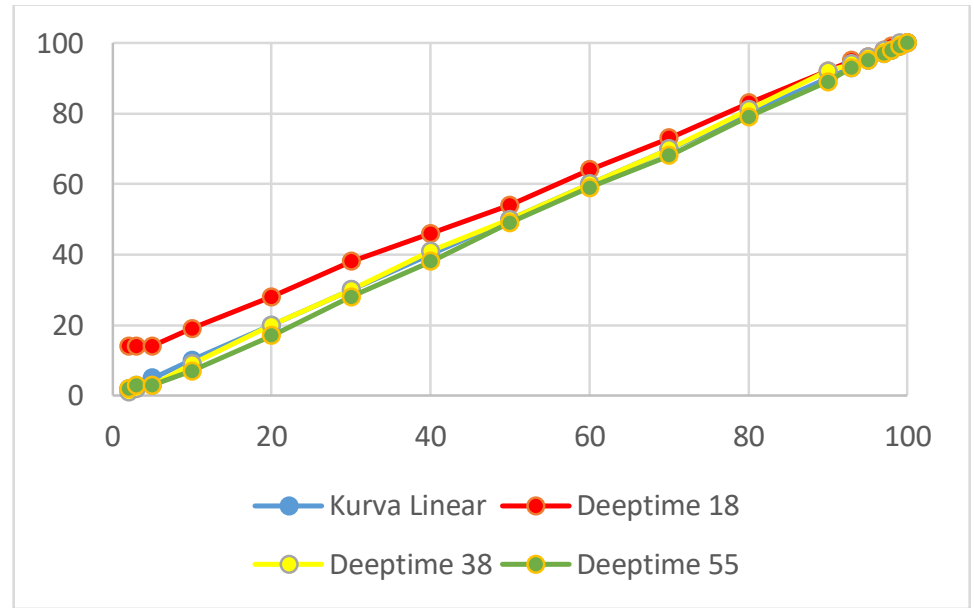

Gambar 9. Percobaan pada Nilai Keseluruhan Dip Time 18, 38 dan 55 